\title{
Contribuições do uso de Redes Sociais Virtuais para o Empreendedorismo Feminino
}

\author{
Contributions of the use of Virtual Social Networks for Female Entrepreneurship
}

\author{
Darah de Mathias Fontana ${ }^{1}$ \\ Deyvison de Lima Oliveira² \\ Elder Gomes Ramos ${ }^{3}$ \\ Ariadne dos Santos Massaro ${ }^{4}$
}

\begin{abstract}
Resumo
Mesmo diante da intensificação do uso de redes sociais nos pequenos e médios empreendimentos liderados por mulheres no país, os benefícios de uso desses recursos para o empreendedorismo feminino são pouco conhecidos na literatura e prática empresarial. Assim, esta pesquisa busca identificar quais as contribuições do uso de redes sociais virtuais (RSV) para o empreendedorismo feminino. Para isto, foram realizados estudos de casos múltiplos com três empreendedoras do Cone Sul do estado de Rondônia que usam intensivamente as RSV. Foram utilizadas entrevistas com as empreendedoras e com uma especialista em empreendedorismo feminino, além de observação direta de suas RSV. Por meio de levantamento prévio da literatura, foi possível identificar nove potenciais contribuições do uso de RSV para o negócio. Todas as contribuições encontradas na literatura foram percebidas pelas entrevistadas, além de duas contribuições adicionais: a contribuição das RSV para a demanda inicial de clientes e a importância das RSV para a manutenção do empreendimento, mesmo depois da sua consolidação no mercado.
\end{abstract}

Palavras-chave: empreendedorismo; gênero; redes sociais virtuais; negócios online; empreendedorismo feminino.

\begin{abstract}
Even with the intensification of social networks use in small and medium enterprises led by women in the country, the benefits of using these resources for female entrepreneurship are little known in the literature and business practice. Thus, this research seeks to identify which are the contributions of virtual social networks (VSN) use for female entrepreneurship. For this purpose, multiple case studies were carried out with three female entrepreneurs from the Southern Cone in Rondônia State, who use VSN intensively. Interviews with female entrepreneurs and a female entrepreneurship specialist were used, in addition to direct observation of their VSN. Through a previous survey of the literature, it was possible to identify nine potential contributions of the use of RSV to the business. All the contributions found in the literature were perceived by the interviewees, besides two additional contributions: the contribution of VSN to the initial customer demand and the importance of VSN for the maintenance of the enterprise, even after its consolidation in the Market.
\end{abstract}

Keywords: entrepreneurship; genre; virtual social networks; online business; female entrepreneurship.

19 Graduada em Administração (Universidade Federal de Rondônia).

Doutor em Administração (EA/UFRGS), professor do Departamento de Ciências Contábeis, Universidade Federal de Rondônia - Campus de Vilhena. Mestre em Administração (FEAD/MG), professor do Departamento de Ciências Contábeis, Universidade Federal de Rondônia - Campus de Vilhena.

Especialista em Auditoria, Contabilidade e Planejamento Tributário (UNESC/RO). 


\section{INTRODUÇÃO}

O número de empreendedores no Brasil tem apresentado crescimento a cada ano. De acordo com o Sebrae, no terceiro trimestre de 2018 havia 27,93 milhões de empreendedores no país (Sebrae, 2018a). Ainda, em 2018, cerca de 52 milhões de brasileiros entre 18 e 64 anos estavam liderando alguma atividade empreendedora (Global Entrepreneurship Monitor, 2018). Destaca-se também que os pequenos negócios no Brasil (microempreendedores individuais, microempresas e empresas de pequeno porte) representam $88,22 \%$ do total de empresas do país e que, entre 2009 e 2014, aumentaram 151\% (Sebrae, 2014).

Apesar de os homens ainda serem maioria no empreendedorismo brasileiro, as mulheres apresentam taxas de empreendedorismo inicial (TEA) muito próximas às dos homens. Ressalta-se, também, que quase metade dos microempreendedores individuais $(47,6 \%)$ são mulheres (Sebrae, 2019). Além disso, do total de empreendedores no Brasil no terceiro trimestre de 2018 (27,93 milhões), 33,98\% eram mulheres (Sebrae, 2018b) e dos 52 milhões dos empreendedores da pesquisa Global Entrepreneurship Monitor, 24 milhões são do sexo feminino (Global Entrepreneurship Monitor, 2018).

Outro fato importante é o uso das redes sociais virtuais por parte das empresas, o que se tornou indispensável para alcançar uma vantagem competitiva no mercado, demonstrando ser uma ferramenta eficaz de captação de clientes, além facilitar a forma de comercializar produtos e serviços, promovendo o progresso das empresas que a utilizam (Santos et al., 2019). Segundo o Cetic.br, o percentual de empresas que possuem perfil ou conta próprios em alguma rede social passou de 36\%, em 2012, para 51\%, em 2015 e 65\% em 2017 (Cetic, 2017).

Diante desses números, destaca-se a utilização das tecnologias da informação e comunicação (TICS) por parte das mulheres. De acordo com Sebrae, $81 \%$ das empresárias pesquisadas possuem acesso à internet e a utilizam em seus negócios, principalmente, para: divulgar a empresa (52\%), expor produtos (48\%) e fazer vendas online $(25 \%)$ (Sebrae, 2018c). Salienta-se a presença ativa das empresárias nas redes sociais: $43 \%$ possuem uma página no Facebook, $71 \%$ utilizam o WhatsApp para se comunicar com os clientes e $53 \%$ acreditam que as vendas da sua empresa tenham maior potencial de crescimento nos próximos cinco anos por meio da internet e redes sociais (Sebrae, 2018c).

Redes sociais virtuais são sites que proporcionam aos usuários se conectarem com muitas pessoas, conhecidas ou não, permitindo que se aumente sua visibilidade e popularidade e construa uma reputação e autoridade (Recuero, 2009).

Mesmo diante da intensificação do uso de redes sociais nos pequenos e médios empreendimentos liderados por mulheres no país, os benefícios de uso desses recursos para o empreendedorismo feminino são pouco conhecidos ou discutidos na literatura e na prática empresarial. Diante disso, esta pesquisa busca identificar as contribuições do uso de redes sociais virtuais para o empreendedorismo feminino, com base em casos de uso intensivo de RSV nos empreendimentos.

\section{EMPREENDEDORISMO, GÊNERO E REDES SOCIAIS VIRTUAIS}

Nesta seção serão apresentados conceitos de empreendedorismo e redes sociais virtuais, aspectos do empreendedorismo feminino e as contribuições das RSV para os negócios, a partir da revisão da literatura.

\subsection{Empreendedorismo}

Segundo Verga e Silva (2014), o empreendedorismo pode ser definido como o estudo, descoberta e exploração de novas oportunidades (produtos, serviços, mercados, processos etc.) com o objetivo de criar um negócio. O empreendedor pode ser definido como aquele que cria/abre uma nova empresa, sendo proprietário ou principal responsável por ela (Fernandes, et al., 2020).

Dados da pesquisa especializada GEM (Global Entrepreneurship Monitor) apontam que o percentual de empreendedores no Brasil aumentou $11,6 \%$ nos últimos 10 anos, representando $38 \%$ da população brasileira em 2018 . Apontam ainda que, do total de empreendedores iniciais, $61,8 \%$ o são por oportunidade, ou seja, iniciaram o negócio após terem identificado uma demanda de mercado executável, diferente dos empreendedores por necessidade, que iniciam os negócios por falta de outras fontes de geração de renda (Global Entrepreneurship Monitor, 2018).

Dada a relevância do empreendedorismo e dos empreendedores no Brasil, pesquisadores têm expandido o campo de pesquisa sobre o tema. Inicialmente, os estudos buscavam entender as características dos empreendedores; evoluindo para a compreensão das práticas e competências empreendedoras, educação para o empreendedorismo, empreendedorismo sustentável e empreendedorismo feminino (Gimenez et al., 2017).

Apesar de a taxa de empreendedorismo inicial (TEA) em 2018 ser maior entre os homens (18,5\% contra 17,3\% das mulheres), percebe-se um equilíbrio entre os gêneros e ressalta-se que, em 2016 e 2017, as TEAs femininas foram superiores às masculinas (Global Entrepreneurship Monitor, 2018). Ressalta-se também que, em 2017, 53\% das mulheres abriram o negócio por oportunidade (IBQP, 2018) e que o Brasil tem a $7^{\mathrm{a}}$ maior proporção de mulheres entre os empreendedores iniciais em relação a 49 países (Sebrae, 2019). 


\subsection{Gênero e empreendedorismo}

Com as mudanças na sociedade, mercado de trabalho e na academia, há um amadurecimento do campo de pesquisa sobre empreendedorismo feminino, inicialmente focado nas motivações para empreender, no perfil da mulher empreendedora e na indicação das diferenças demográficas entre homens e mulheres (Gomes et al., 2014), evoluindo para uma compreensão dos laços e relacionamentos sociais como pontos centrais do empreendedorismo feminino, além da análise dos conflitos relacionados às múltiplas funções exercidas pelas mulheres, como o papel de mãe, esposa e dona do negócio. No entanto uma vertente pouca estudada é o fomento ao empreendedorismo feminino (Gimenez et al., 2017).

Após a revolução sexual de 1960 e a conquista dos direitos civis das mulheres, as empreendedoras começaram uma busca contínua pela emancipação pessoal e financeira (Nunes , 2009). A motivação para abrir um negócio próprio surge da necessidade de maior liberdade, flexibilidade, autorrealização e de uma incrementação na carreira (Ferreira et al., 2018). Elas buscam a independência por meio de uma fonte de renda própria, estando no comando dos negócios (Silva et al., 2016).

Silva e Guimarães (2018), em seu estudo, constataram que a maioria das mulheres pesquisadas optou pelo empreendedorismo em busca de autonomia para estipular seus horários e metas, terem mais tempo disponível e a possibilidade de conciliar trabalho e família. Já Jonathan (2006) identificou que as empreendedoras se dedicam ao negócio como forma de externar seus valores e desenvolver suas ideias.

O início do negócio se dá, geralmente, de maneira mais informal, na própria casa da empreendedora ou em local cedido por parentes e amigos. Os primeiros clientes fazem parte da sua rede de conhecidos e o marketing é feito por meio da rede informal (Alperstedt et al., 2014).

Quanto à identificação de oportunidades, Freitas e Teixeira (2016) citam que as empreendedoras se baseiam em diversos fatores, tais como o sucesso de um empreendimento anterior e/ou de terceiros, o histórico familiar e demandas não atendidas, as quais muitas vezes são sinalizadas pelos próprios clientes. Eles afirmam que "a intuição, as habilidades interpessoais e o forte apoio familiar são determinantes na identificação das oportunidades de criação e continuidade dos negócios" (Freitas e Teixeira, 2016, p. 104). Apesar de parte da sociedade ainda perceber a mulher como a grande responsável por cuidar da casa e dos filhos, elas não desistiram de criar suas empresas e de buscar soluções criativas para lidar com a multiplicidade de papéis (Alperstedt et al., 2014; Jonathan, 2006).

Ao ingressar no empreendedorismo, as mulheres também estão mais suscetíveis aos riscos (Silva et al., 2016). Adicionalmente, elas enfrentam barreiras à atuação no mercado, tendo que buscar formas de superá-las com capital humano, capital social e práticas gerenciais diferenciadas (Bertolami et al., 2018).

De acordo com Alperstedt et al. (2014), os maiores desafios enfrentados pelas mulheres entrevistadas foram: o preconceito por empreenderem em setores "masculinos"; o fato de serem jovens; a necessidade de conciliar os papéis de mãe, esposa e empresária; a obtenção de recursos financeiros e de gestão; e a maior demora para ganhar reconhecimento. Souza et al. (2016), adicionalmente, apontam que os problemas enfrentados pelas empreendedoras foram as barreiras culturais, dificuldade de acesso a redes; e de conciliar trabalho e família, entre outros.

\subsection{Valor de negócio das redes sociais virtuais}

Nas últimas décadas as redes sociais virtuais tornaram-se alvo de diversas pesquisas devido à importância cada vez maior que têm demonstrado no âmbito da difusão de informação e comunicação, sendo responsáveis por mudanças no modo como as pessoas se relacionam (Correio et al., 2016). De acordo com Recuero (2009), redes sociais são locais utilizados para a expressão na internet e permitem aos atores aumentar suas conexões sociais.

As formas de se relacionar e fazer negócio com os clientes mudou após as transformações no comportamento da sociedade decorrentes das inovações tecnológicas. As empresas precisam se adaptar a esse novo contexto e utilizar novos recursos disponíveis, a exemplo das RSV, como forma de auxiliar as estratégias de relacionamento e cocriação de valor (Formanski et al., 2013). O uso de estratégias em redes sociais é uma ferramenta bastante eficaz, pois auxilia no aumento da visibilidade da empresa, atrai novos clientes, favorece a proximidade, o relacionamento e a fidelização de clientes, além de, consequentemente, aumentar índice de vendas (Ferreira et al., 2019).

De acordo com Recuero (2009), o uso das redes sociais pode gerar valor em quatro aspectos para o usuário, sendo eles: a) visibilidade: o uso das redes sociais torna o usuário mais visível aos demais usuários, ampliando seu alcance e o tornando mais popular; b) reputação: torna-se possível construir uma reputação baseada nas opiniões e percepções dos usuários sobre aquele indivíduo; c) popularidade: está diretamente ligada ao tamanho da sua audiência, que pode ser mensurada pelo número de seguidores, por exemplo; d) autoridade: é a efetiva influência que o usuário tem sobre seus seguidores, resultado dos demais valores citados anteriormente.

As empresas mantêm ações nas redes pelo fato de que elas proporcionam uma rápida e simples interação com o usuário, oferecendo conteúdo e prestação de serviços que contribuam para a construção do relacionamento com seus clientes (Rocha et al., 2013). Nesse contexto, as empresas estão cada vez mais dependentes das RSV para interagir com seus clientes, que, por sua vez, as utilizam para buscar e publicar informações sobre suas experiências 
com as empresas (Batista, Gaspar \& Sassi, 2020).

Dentre as RSV usadas, observa-se: o Facebook, utilizado com o objetivo de aumentar o relacionamento com o cliente (Rocha et al., 2013); aplicativo de mensagens (e.g. WhatsApp), utilizados para aproximar e fidelizar o consumidor, visto que seus atributos permitem uma comunicação mais pessoal por meio de grupos, além de receber sugestões, dúvidas e reclamações (Ferreira e Arruda Filho, 2015); e o Instagram, que é uma rede social centrada na imagem, onde as empresas identificaram um grande potencial de influência e recomendação da marca por parte dos usuários (Conceição, 2020). Portanto, as redes sociais são uma ferramenta de relacionamento com o cliente, auxiliando no processo de comunicação e interação da empresa com seus consumidores (Desidério et al., 2017).

As RSV possibilitam a segmentação dos seguidores por meio da ferramenta de anúncios, o que proporciona às empresas estarem mais próximas de clientes atuais e potenciais, visto que a comunicação e interação é mais facilitada nesse ambiente. Dessa forma, gestores hoteleiros, por exemplo, as utilizam para divulgar serviços e promoções com publicações diárias que reforçam a marca na mente do cliente e a torna visível para novas pessoas. A captação de clientes ocorre do mesmo modo, pois o Facebook (por exemplo) permite que o cliente faça reserva através da página da empresa. Os gestores hoteleiros afirmam receber entre $50 \%$ e $80 \%$ de suas demandas pelas redes sociais (Gomes e Mondo, 2016). As RSV "geram tráfego e, consequentemente, cadastros que geram leads e podem vir a conduzir além da disseminação de conteúdos e de informações, também vendas" (Pinochet et al., 2018, p. 95). Portanto, as RSV são um instrumento para a captação e manutenção de clientes, em que o direcionamento das publicações e ofertas para o público-alvo gera resultados positivos para a empresa (Visentini et al., 2017).

A imagem transmitida pela empresa é fundamental também para o processo de faturamento, venda de produtos e serviços, e para o crescimento do negócio. Por isso, preocupar-se com a exteriorização de marca/produto/serviço passa a ser uma necessidade para as empresas (Terra, 2013). Outra evidência das contribuições das redes sociais para as vendas foi confirmada por MacLennan et al. (2014) ao identificarem que a intensidade de acesso às mídias sociais, ou seja, o tempo que o usuário fica online nas redes, influencia em sua decisão de compra.

Os recursos disponíveis nas redes sociais apresentam outras vantagens em relação às mídias offline: são mais fáceis de serem mensurados e possuem um menor custo. $O$ valor pago a uma empresa de publicidade para fazer postagens nas redes sociais, quando comparado ao valor de outras mídias, como rádio e TV, é irrisório (Gomes e Mondo, 2016).

As vantagens da possibilidade de mensuração dos resultados obtidos das publicações pelas empresas são: gestão da reputação; suporte ao consumidor; proteção da marca; benchmarking; pesquisa de mercado; exposição da marca; pesquisa de marketing; mensuração de campanha; segmentação de público; mapeamento de influenciadores; geração de leads; inovação; entre outros (Pinochet et al., 2018). O uso de métricas das RSV permite saber se a estratégia utilizada pela empresa está sendo efetiva para o objetivo final, que abrange conquistar mais clientes, aumentar suas vendas, ganhar posicionamento, entre outros. Portanto, as métricas são indispensáveis no mundo digital, dado que as empresas precisam não só manter um perfil nas redes mais relevantes no momento, mas conservá-las constantemente atualizadas, com informações pertinentes de seus produtos e serviços para seu público (Pinochet et al., 2018).

Do exposto, entende-se que as RSV se tornaram um canal de relacionamento e interação com o cliente, contribuindo para a cocriação de valor em várias áreas do empreendimento. Por meio delas, é possível a colaboração dos clientes, respostas rápidas por parte da empresa, além de custos financeiros reduzidos para essas operações (Formanski et al., 2013).

As RSV têm um papel imprescindível para o marketing digital de mulheres empreendedoras e são importantes formas mediatizadas de divulgação e comercialização, independentemente da localização geográfica do empreendimento (Brandão, 2016). À proporção que os empreendimentos disponibilizam seus produtos e serviços na internet, fortalecem a marca e, consequentemente, ampliam suas receitas, tornando-se autossustentáveis e proporcionando a emancipação dessas mulheres empreendedoras na perspectiva do desenvolvimento socioeconômico local e regional (Brandão, 2016).

Nessa linha, de acordo com Braga e Coelho (2018), blogueiras estão utilizando as redes sociais como meio de se comunicar e interagir com seus seguidores e leitores, divulgar seus produtos e também reforçar a sua marca. Elas utilizam as redes sociais em quatro etapas: promoção, propagação, personalização e precisão. Segundo os autores, para a promoção, utilizam principalmente o Instagram, o Snapchat, o Twitter e o Facebook, afirmando serem as redes mais eficazes. Na propagação, utilizam postagens que incentivam a interação dos seguidores para aumentar o engajamento. Na personalização, o objetivo é aproximar os leitores por meio de conteúdos sugeridos por eles e de uma conversa mais pessoal. Por fim, na etapa da precisão, elas utilizam as RSV para mensurar resultados, como a rentabilidade e o alcance das publicações. Elas utilizam esses dados para firmar parcerias com empresas que as procuram para divulgar seus produtos. Os números mais importantes para elas não são do blog, mas, sim, das RSV (Braga e Coelho, 2018).

De acordo com a literatura mencionada nesta seção, foi elaborada a Tabela 1, que apresenta um resumo das contribuições do uso de RSV (valor de negócio). 
Tabela 1 - Contribuições do uso de redes sociais virtuais para o negócio

\begin{tabular}{|l|l|}
\hline \multicolumn{1}{|c|}{ Contribuições das RSV } & \multicolumn{1}{c|}{ Fundamento } \\
\hline Interação/relacionamento com o cliente & $\begin{array}{l}\text { (Rocha et al., 2013); (Ferreira e Arruda Filho, 2015); (Desidério et al., 2017); (Gomes e } \\
\text { Mondo, 2016); (Formanski et al., 2013); (Braga e Coelho, 2018). }\end{array}$ \\
\hline Fortalecimento e influência da marca & (Gomes e Mondo, 2016); (Brandão, 2016); (Braga e Coelho, 2018); (Recuero, 2009). \\
\hline Custos menores & (Gomes e Mondo, 2016); (Formanski et al., 2013). \\
\hline Mensuração de resultados mais facilitada & (Pinochet et al., 2018); (Braga e Coelho, 2018). \\
\hline Divulgação de produtos e da empresa & $\begin{array}{l}\text { (Gomes e Mondo, 2016); (Brandão, 2016); (Braga e Coelho, 2018); (Rocha et al., 2013); } \\
\text { (Pinochet et al., 2018). }\end{array}$ \\
\hline Canal de vendas & (Gomes e Mondo, 2016); (Pinochet et al., 2018); (MacLennan et al., 2014); (Brandão, 2016). \\
\hline Emancipação financeira & (Brandão, 2016). \\
\hline Captação de clientes & (Gomes e Mondo, 2016); (Visentini et al., 2017). \\
\hline Maior visibilidade e alcance da empresa & (Gomes e Mondo, 2016); (Braga e Coelho, 2018); (Recuero, 2009). \\
\hline
\end{tabular}

Fonte: Elaboração própria.

Para subsidiar a análise de dados apresenta-se o modelo de pesquisa (Figura 1).

Figura 1 - Modelo conceitual de pesquisa

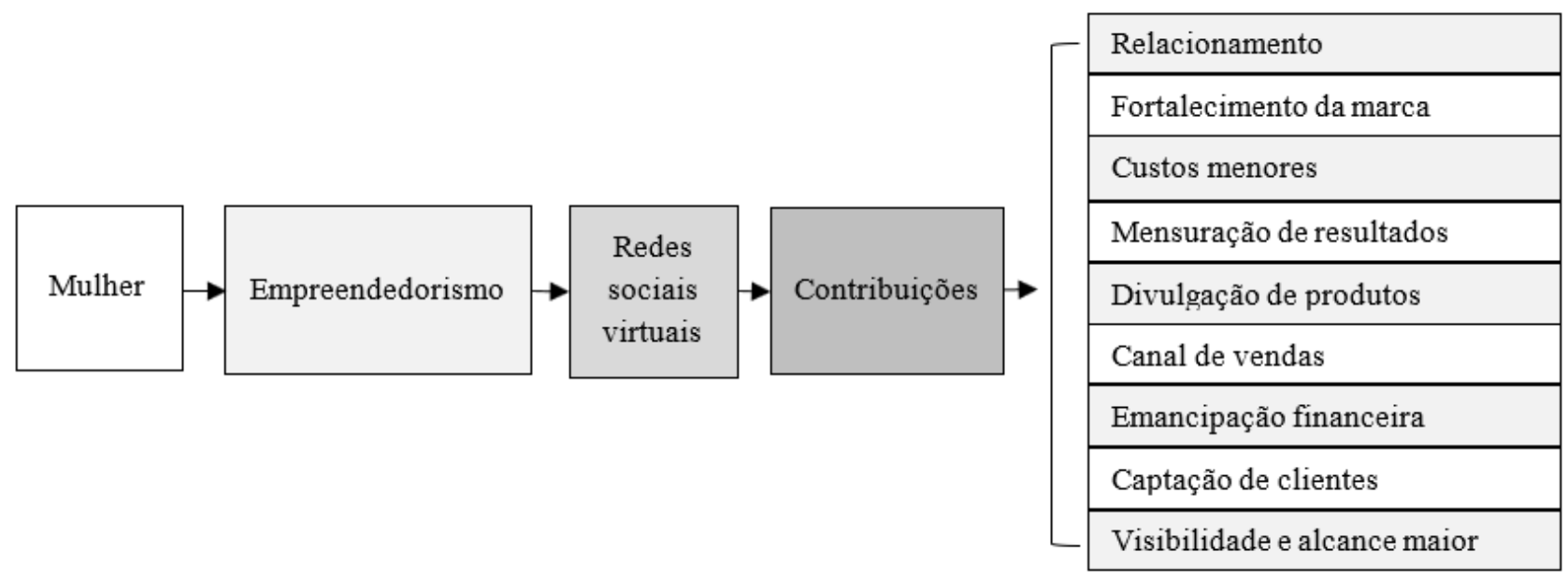

Fonte: Elaboração própria.

\section{MÉTODOS}

\subsection{Procedimentos metodológicos}

O procedimento metodológico utilizado foi o estudo de caso que, segundo Yin (2005, p. 32), "é uma investigação empírica que investiga um fenômeno contemporâneo dentro de seu contexto da vida real, especialmente quando os limites entre o fenômeno e o contexto não estão claramente definidos". De acordo com Gil (2008), o estudo de caso investiga com profundidade o objeto, possibilitando resultados com maior riqueza de detalhes. Pelo fato de o fenômeno estudado nesta pesquisa ainda apresentar resultados exploratórios na literatura, o estudo de caso permite que os pesquisadores se aprofundem nos casos, extraindo resultados mais completos sobre cada um.

Os casos utilizados nesta pesquisa são mulheres donas do negócio que iniciaram sozinhas seus empreendimentos e que possuem resultados expressivos (mais de 10 mil seguidores) nas redes sociais virtuais.

Esta pesquisa caracteriza-se como exploratória, visto que tem como objetivo disponibilizar uma visão ampla acerca do problema pesquisado e que o tema ainda é explorado de forma incipiente pela literatura (Gil, 2008).

\subsection{Coleta de dados}

As técnicas utilizadas para a coleta de dados foram: entrevista semiestruturada com empreendedoras, observação direta das RSV e entrevista com especialista da área. A entrevista foi escolhida por permitir a captação de dados com maior profundidade e detalhamento. Ela é guiada por uma estrutura formulada anteriormente, mas 
permite certo grau de flexibilidade tanto para o entrevistado quanto para o entrevistador (Gil, 2008).

A entrevista foi realizada com empreendedoras de três casos do Cone Sul de Rondônia. Os casos foram escolhidos por serem destaques na região e pela relevância que apresentam: todos trabalham há pelo menos quatro anos, são notoriamente reconhecidos na região pela inovação, usam intensivamente (possuem muitas publicações em suas redes e dedicam muitas horas do dia a elas) as redes sociais no negócio, possuem um número de seguidores acima da média da região, sendo um deles com alcance mundial, exportando seus produtos para o mundo todo, e utilizam as RSV como um canal de vendas do negócio. A entrevista foi gravada e, posteriormente, os dados foram transcritos, agrupados e analisados.

Foi realizada uma entrevista de pré-teste com uma empreendedora local, a fim de ajustar as perguntas formuladas e o protocolo do estudo de caso. Após o pré-teste cinco perguntas foram retiradas, duas perguntas foram reformuladas e duas novas perguntas foram incluídas. Os resultados da entrevista pré-teste não constam dentre os três casos.

Na observação direta foram observadas as redes sociais Facebook e Instagram dos casos durante uma semana, analisando quais recursos eram utilizados, as práticas mais frequentes e a interação com o público - procedendo-se aos registros pertinentes.

A entrevista realizada com a especialista em empreendedorismo feminino foi utilizada como outra fonte de evidências. A especialista escolhida tem 30 anos, é advogada e gestora do projeto Empreendedorismo Feminino SEBRAE Delas - Mulher de Negócio. A coleta de dados foi realizada no primeiro semestre de 2019.

\subsection{Análise de dados}

Para a análise de dados, utilizou-se a análise de conteúdo, que, segundo Bardin (2011), é um conjunto de técnicas que têm por objetivo obter a descrição do conteúdo das diversas mensagens analisadas, possibilitando extrair conhecimento dessas mensagens. De acordo com Vergara (2012), essa técnica é utilizada para pesquisas exploratórias e quando grandes quantidades de dados precisam ser tratadas e analisadas.

Para a análise de conteúdo utilizaram-se as categorias descritas a priori na Tabela 1, as quais descrevem as contribuições do uso de RSV para o empreendedorismo. Buscou-se analisar os dados a fim de concluir se as contribuições apontadas na literatura também são identificadas pelas empreendedoras e se há novas contribuições percebidas das RSV aplicadas a negócios inovadores.

\section{RESULTADOS E DISCUSSÃO}

Esta seção apresenta os dados coletados nas entrevistas com empreendedoras e uma especialista em empreendedorismo feminino, bem como dados da observação direta das redes sociais. Adicionalmente, é apresentada uma discussão sobre os achados à luz da literatura.

As empreendedoras foram denominadas no texto como EA, EB e EC, a fim de manter o sigilo quanto à identificação. A especialista em empreendedorismo feminino será tratada apenas como especialista. As entrevistas foram realizadas pessoalmente com as empreendedoras EA e EC e virtualmente com a empreendedora EB e a especialista.

\subsection{Dados demográficos dos casos}

As empreendedoras possuem média de idade de 28 anos. A EA trabalha no ramo da beleza, prestando serviços como maquiadora e vendendo produtos de maquiagem; a EB possui uma indústria de vestidos para festas; e a EC trabalha como influenciadora digital e também tem empresa de gerenciamento de redes sociais para outros empreendimentos. Elas estão, em média, há cinco anos trabalhando com esses empreendimentos, são as donas do negócio e os gerenciam sozinhas.

Todas afirmaram utilizar intensivamente as redes sociais virtuais (RSV) desde o início do empreendimento, sendo as redes mais utilizadas o Facebook, o Instagram e o WhatsApp. A EA afirma utilizar por três a quatro horas por dia as redes sociais; já a EB tem $50 \%$ do seu tempo pessoal e profissional destinado às redes sociais; e a EC relata que trabalha cerca de doze horas por dia, sempre utilizando as redes sociais. As empreendedoras $\mathrm{B}$ e $\mathrm{C}$ contam com a ajuda de funcionários para alimentar as redes sociais, já a EA cuida de toda as redes sozinha.

\subsection{Recursos utilizados e principais práticas nas redes sociais virtuais}

As RSV oferecem recursos que possibilitam a interação e aproximação com o cliente, o aumento do alcance da empresa dentro da rede social e a análise e mensuração dos resultados. A Tabela 2 foi utilizada para a análise desta seção. Ela apresenta os recursos, descreve as suas funcionalidades e aponta a quais redes sociais estão vinculadas. As RSV citadas são: o Facebook, que permite aos usuários trocar mensagens, compartilhar fotos e vídeos, e interagir com pessoas do mundo todo; o Instagram, que é uma rede social para fotos e vídeos curtos, onde usuários podem 
"seguir" outros usuários; e o WhatsApp, que tem como principal objetivo a troca de mensagens entre os usuários, seja em uma conversa privada, seja em grupos com até 256 pessoas.

Tabela 2 - Recursos disponíveis nas redes sociais virtuais

\begin{tabular}{|c|c|c|}
\hline Recurso & Funcionalidade & Rede social vinculada \\
\hline Comentários & $\begin{array}{l}\text { Possibilitam ao usuário deixar sua opinião (positiva ou não) sobre o conteúdo } \\
\text { publicado. }\end{array}$ & Facebook e Instagram \\
\hline Compartilhamentos & $\begin{array}{l}\text { Possibilitam ao usuário replicar um conteúdo publicado por outro usuário com } \\
\text { a sua rede de contatos. }\end{array}$ & Facebook e Instagram \\
\hline Curtidas & $\begin{array}{l}\text { Disponível nas publicações e comentários, possibilitam ao usuário manifestar } \\
\text { que gostou do conteúdo publicado. }\end{array}$ & Facebook e Instagram \\
\hline Hashtags & $\begin{array}{l}\text { Possibilitam a categorização de palavras-chave, agrupando todas as } \\
\text { publicações que utilizaram a hashtag. }\end{array}$ & Facebook e Instagram \\
\hline Story/status & $\begin{array}{l}\text { Permitem que os usuários publiquem fotos e vídeos rápidos que só podem ser } \\
\text { visualizados por } 24 \text { horas. }\end{array}$ & Facebook, Instagram e WhatsApp \\
\hline Marcar pessoas & $\begin{array}{l}\text { Permite ao usuário colocar o nome de outro usuário em uma publicação, } \\
\text { comentário ou story. }\end{array}$ & Facebook e Instagram \\
\hline $\begin{array}{l}\text { Impulsionamento/ } \\
\text { anúncio }\end{array}$ & $\begin{array}{l}\text { Permite ao usuário pagar para que uma publicação seja exibida para uma lista } \\
\text { de pessoas segmentadas por características como idade, sexo e interesses. }\end{array}$ & Facebook e Instagram \\
\hline Análise de dados & $\begin{array}{l}\text { Permite ao usuário analisar os dados gerados pela própria rede social sobre } \\
\text { os resultados daquele perfil. }\end{array}$ & Facebook e Instagram \\
\hline Enquete & $\begin{array}{l}\text { Permite ao usuário realizar uma enquete com duas opções de voto e calcula } \\
\text { os resultados automaticamente. }\end{array}$ & Facebook e Instagram \\
\hline Chat & $\begin{array}{l}\text { Permite ao usuário ter uma conversa privada ou em grupo com outros usuários } \\
\text { dentro da própria rede social. }\end{array}$ & Facebook, Instagram e WhatsApp \\
\hline
\end{tabular}

Fonte: Elaboração própria.

A EA recebe poucos comentários em publicações no Facebook e Instagram, mas sempre responde a todos, com o objetivo de se mostrar presente para seus clientes. Os comentários são uma fonte de captação de feedbacks e de falhas de comunicação, como afirma a EB: "a gente utiliza em forma de feedback e consegue perceber nos comentários coisas que não ficaram claras e a aceitação de um produto". No entanto ela não consegue responder a todos devido ao grande número de comentários que recebe. Para a EC, "se você não responde o cliente, a impressão que dá é que tem uma máquina ali". Contudo a observação direta evidenciou que poucas publicações das suas redes sociais recebem comentários e a maioria não é respondida.

Os compartilhamentos ajudam a entender o interesse no público. Segundo a EA, "isso ajuda para a gente ter uma noção se a publicação tá legal e qual teve mais interação do público". A EB usa os números de compartilhamentos como parâmetro para saber se o produto foi bem aceito ou não. Os compartilhamentos têm papel fundamental para o aumento do alcance das publicações, conforme afirma a EC: "eu consigo de três a quatro vezes mais visualização do que através de impulsionamento [pagar para a publicação chegar a mais pessoas]".

As curtidas são usadas como direcionador, entendendo qual tipo de conteúdo os seguidores gostam de ver. A EA afirma: "no Instagram, eu percebo que tem mais curtidas em fotos pessoais e fotos que têm alguma dica". Fotos em que a empreendedora aparece utilizando o produto têm cerca de dez vezes mais curtidas que fotos em que aparece somente o produto.

Para a EB, as curtidas são o que mais têm relevância, pois elas influenciam no engajamento da publicação e fazem-na chegar a mais clientes. Para a EC, as curtidas não geram resultados, e outros indicadores são mais importantes. Suas publicações são mais curtidas no Facebook que no Instagram, mas possuem um baixo número de curtidas quando comparado às empreendedoras A e B. As hashtags não mostraram ser de grande importância para as três empreendedoras, embora elas façam uso do recurso e admitam que ele traz benefícios.

O story é classificado como o recurso mais relevante. Elas dão muita atenção ao recurso, postando, em média, dez stories por dia. O conteúdo mescla vida pessoal, bastidores do negócio e divulgação dos produtos e serviços. A EA utiliza o recurso para conhecer seu público, mostrar seu dia a dia (com o objetivo de se aproximar do cliente) e divulgar produtos. A EA afirma que "o story é o essencial. Atingem um público muito maior do que uma publicação no feed e você consegue saber quem são as pessoas que têm o hábito de te acompanhar mais".

A EB não passa um dia sem postar no story. Segundo ela, "é muito importante... a interação, os comentários, 
a forma como o cliente interage rapidamente... a gente não deixa de alimentar o story nenhum dia". Para a EC, o principal objetivo é mostrar que existe uma pessoa por trás da marca: "eu amo! Eu faço um monte se deixar, para eles saberem que eu sou uma pessoa e que tenho sentimentos".

Quanto a enquetes e perguntas, a EA utilizou esses recursos para a tomada de decisão de abrir uma nova loja: "antes de abrir a loja, eu fiz uma enquete para análise de mercado, porque ali tem o público que eu preciso, e você vê o resultado instantâneo. Se eu tivesse que fazer no papel, eu nem teria público pra isso". EB e EC também utilizam com frequência esse recurso.

A empreendedora EA utiliza o recurso de impulsionamento e tem resultados positivos com ele: "você consegue segmentar muito específico, colocar a idade, a cidade, se é um público feminino... traz resultados e é muito barato". EB e EC já utilizaram o recurso, mas conseguem os mesmos resultados de maneira orgânica, sem a necessidade do investimento.

Quanto à análise dos dados gerados pelas próprias redes sociais (número de curtidas, comentários e compartilhamentos, número de visitas ao perfil e cliques no link, dados demográficos dos seguidores e número de pessoas alcançadas), EA e EB analisam-nos e utilizam-nos para a tomada de decisão e ajuste da estratégia utilizada. Elas também afirmam que, se as redes sociais não gerassem os dados automaticamente, seria mais difícil de ter esses dados manualmente e possivelmente não fariam esse tipo de análise. Já a EC utiliza os dados para divulgar seu próprio trabalho, pelo fato de ser uma influenciadora. Quanto à ferramenta de chat, todas utilizam, principalmente para fechar vendas, tirar dúvidas dos clientes e marcar horários. A rede social mais utilizada para essa prática é o WhatsApp.

As redes sociais são o principal canal de vendas das três empreendedoras. Mesmo a EA e EB possuindo loja física, elas afirmam que as pessoas só vão até a loja porque as viram nas redes sociais. Já a EC faz tudo através das redes sociais: "é tudo através das redes sociais. As pessoas contratam a gente pelo WhatsApp, eu mando o contrato pelo WhatsApp, os dados, faço os boletos, e ali já começo".

\subsection{Objetivos do uso de redes sociais virtuais: percepção das empreendedoras}

O principal objetivo das três empreendedoras ao usar as RSV é a divulgação de seus produtos. A EA também busca ser sempre lembrada pelos clientes: "conseguir clientes no geral, divulgar produtos e ser visualizada, porque quando você não está participando de uma rede social, hoje em dia, acaba que você cai no esquecimento".

AEB afirma, como objetivo de uso das RSV, "divulgar o nosso produto e captar os possíveis clientes interessados naquele produto". A EC, por ser influenciadora, afirma também que seu principal objetivo é o sucesso dos seus clientes: "hoje, meu objetivo é que meus clientes vendam e tenham sucesso".

A EA vende seus produtos para outras cidades e estados vizinhos, e afirma que essa prática só é possível graças às redes sociais: "as redes sociais contribuíram para isso, com certeza. Sem elas eu acho que seria mais difícil, porque daí seria só boca a boca... Poderia atingir, mas seria um processo de muito mais anos". A EB exporta seus produtos com frequência para cerca de vinte países, além de vender para todos os estados brasileiros. Ela também acredita que isso não seria possível sem as RSV: "eu não vejo outra maneira de ter esse alcance a não ser através das redes sociais". Já a EC não tem clientes em outras cidades, apenas seguidores.

Quanto ao custo/benefício de se utilizar as redes sociais, a EA afirma: "é o mais em conta e o que atinge maior resultado". A EB afirma ter somente benefícios: "na verdade, é só benefício, porque o custo é muito baixo". Já para a EC há uma relação menos vantajosa que as outras empreendedoras: "mais ou menos, porque o profissional é caro. Se eu soubesse fazer tudo, eu nem precisaria mais advogar, porque iria suprir". Para as empreendedoras, as RSV contribuíram para o reforço da sua marca/nome na mente dos clientes e para a influência delas. Segundo EA, seria muito mais difícil influenciar seus clientes para a compra sem as redes sociais.

A receita gerada pelo empreendimento proporciona à EA e EB independência financeira, e as redes sociais contribuíram para isso. A EA afirma: "contribuiu totalmente, porque, como eu usei as redes sociais desde o começo, elas foram o essencial para eu conseguir clientes". Já a EC ainda não é independente financeiramente, apenas em decorrência da receita do seu empreendimento, mas por questões de inadimplência dos clientes: "não é um dinheiro que eu posso contar todo mês, mas, se todos pagarem certinho, eu não preciso trabalhar o ano inteiro".

As RSV se mostraram relevantes desde o início dos empreendimentos até o momento atual, proporcionando resultados que não seriam possíveis sem elas. Para a EA, as RSV foram importantes para tudo desde o início do seu negócio. Ela as utilizou para ser mais conhecida na cidade, para atingir mais pessoas e para transformá-las em clientes, como afirma: "Sem as redes sociais talvez eu não teria conseguido o que eu consegui hoje. Eu não teria aberto meu negócio, não estaria onde estou, eu não conseguiria atingir o público que eu atinjo".

Para a EB, as RSV viabilizaram trabalhar na sua área de formação sem precisar estar nas regiões mais populosas do país. Nesse sentido, EB conclui: "hoje, as redes sociais são a base para a existência da minha empresa. Se não existissem eu não teria começado esse negócio".

Para a EC, as respostas rápidas das ações nas RSV Ihe proporcionaram crescer num ritmo que empreendimentos offline não proporcionariam. Para ela, as RSV só lhe trouxeram coisas boas e lhe oportunizaram ajudar pessoas, algo que a motiva. Ela conclui afirmando: "o meu negócio é nas redes sociais, sem elas ele nem existiria". 


\subsection{Uso de redes sociais virtuais: percepção da especialista}

A especialista entrevistada é gestora do Sebrae DELAS - Mulher de Negócio. Neste projeto, ela tem contato com setenta mulheres selecionadas para receberem acompanhamento técnico em diversas áreas do negócio, entre elas, o marketing.

A especialista afirma que $90 \%$ das mulheres que acompanha fazem uso das RSV no negócio. Ela afirma que sempre sugere o uso das redes para o negócio. Além disso, relata que já acompanhou algumas empreendedoras dando orientações sobre o uso eficiente das redes.

Para a especialista, as principais contribuições do uso das RSV são a "globalização" (não possuem barreiras geográficas) e a "democracia", pois permitem que empreendedoras que não têm alto grau de escolarização tenham acesso a essa tecnologia e vendam pela internet. Ela também acredita que as RSV podem motivar as mulheres a abrirem um novo negócio, colaborando para o empreendedorismo como um todo. Ela destaca que as redes sociais são atrativas pelo fato de poderem ser facilmente acessadas, e seu uso é voltado principalmente para a divulgação dos negócios atuais e para fazer novos negócios.

\subsection{Discussão}

Na Tabela 3 é apresentado o resumo das percepções das empreendedoras e da especialista em relação às contribuições do uso de redes sociais virtuais para o empreendedorismo feminino.

Os resultados da pesquisa corroboram os achados da literatura (Brandão, 2016; Formanski et al., 2013; Gomes e Mondo, 2016; Pinochet et al., 2018; Recuero, 2009; Rocha et al., 2013; Visentini et al., 2017). Todas as nove contribuições citadas no referencial revisado são percebidas pelas empreendedoras e pela especialista, evidenciando que as RSV estão se mostrando cada vez mais importantes para o empreendedorismo feminino, servindo como uma ferramenta de incentivo ao empreendedorismo, pois possibilitam que qualquer mulher, independentemente do status social, nível educacional ou situação financeira, possa iniciar um negócio e vender nas redes sociais. Isso confirma que as redes sociais virtuais têm um papel imprescindível para o marketing digital dos empreendimentos femininos e são importantes formas mediatizadas de divulgação e comercialização, independentemente da localização geográfica do empreendimento (Brandão, 2016).

Foi possível identificar que o uso das RSV tem gerado valor para os empreendimentos pesquisados nos quatro aspectos citados por Recuero (2009), isto é, a visibilidade, a reputação, a popularidade e a autoridade. Também foi identificado o uso nas quatro etapas citadas por Braga e Coelho (2018), a saber, para a promoção, a propagação, a personalização e a precisão do negócio. Nesse sentido, pode-se observar que as RSV são usadas em vários aspectos e etapas do empreendimento, tornando-se relevantes não apenas em uma fase do negócio, mas para o empreendimento como um todo.

Em síntese, constata-se que as contribuições do uso de RSV para o empreendedorismo feminino são confirmadas e podem ser potencializadas quando essas redes são usadas de maneira adequada e consciente. As RSV podem impulsionar o empreendimento e viabilizar um negócio que, anteriormente, não seria possível.

Tabela 3 - Contribuições do uso de RSV para o empreendedorismo feminino

\begin{tabular}{|l|l|l|l|}
\hline \multicolumn{1}{|c|}{ Contribuições } & \multicolumn{1}{|c|}{ Literatura } & \multicolumn{1}{c|}{ Empreendedoras femininas } \\
\hline $\begin{array}{l}\text { Interação e } \\
\text { relacionamen-to com } \\
\text { os clientes }\end{array}$ & $\begin{array}{l}\text { Rápida e simples interação com o } \\
\text { usuário e relacionamento com clientes } \\
\text { (Rocha et al., 2013). }\end{array}$ & $\begin{array}{l}\text { Recursos como comentários e stories } \\
\text { proporcionam maior interação e } \\
\text { relacionamento com clientes. }\end{array}$ & $\begin{array}{l}\text { As RSV proporcionam um } \\
\text { relacionamento mais próximo } \\
\text { com os clientes. }\end{array}$ \\
\hline $\begin{array}{l}\text { Fortalecimen-to e } \\
\text { influência da marca }\end{array}$ & $\begin{array}{l}\text { As publicações diárias reforçam a } \\
\text { marca na mente do cliente e a torna } \\
\text { visivel para novas pessoas (Gomes e }\end{array}$ & $\begin{array}{l}\text { Presença diária na rotina dos } \\
\text { seguidores com dicas e informações } \\
\text { dos produtos. }\end{array}$ & $\begin{array}{l}\text { Visibilidade diária pelo } \\
\text { cliente sem necessidade de } \\
\text { deslocamento do mesmo. }\end{array}$ \\
\hline $\begin{array}{l}\text { Custos menores em } \\
\text { relação a outros tipos } \\
\text { de mídias }\end{array}$ & $\begin{array}{l}\text { Custos reduzidos para ações, como } \\
\text { colaboração dos clientes e respostas } \\
\text { rápidas por parte da empresa } \\
\text { (Formanski et al., 2013). }\end{array}$ & $\begin{array}{l}\text { A percepção de custo/benefício é } \\
\text { muito alta pela gratuidade do uso das } \\
\text { RSV e do baixo custo dos anúncios. }\end{array}$ & $\begin{array}{l}\text { Não possuem custos para } \\
\text { utilização e podem ser } \\
\text { impulsionadas por um valor } \\
\text { menor que outras mídias. }\end{array}$ \\
\hline
\end{tabular}

Fonte: Elaboração própria, adaptada da literatura. 
Tabela 3 - Contribuições do uso de RSV para o empreendedorismo feminino (continuação).

\begin{tabular}{|c|c|c|c|}
\hline Contribuições & Literatura & Empreendedoras femininas & Especialista \\
\hline $\begin{array}{l}\text { Mensuração de } \\
\text { resultados mais } \\
\text { facilitada }\end{array}$ & $\begin{array}{l}\text { Os dados possibilitam a gestão da } \\
\text { reputação, suporte ao consumidor, } \\
\text { benchmarking e pesquisa de mercado, } \\
\text { mensurar campanhas e segmentar o } \\
\text { público (Pinochet et al., 2018). }\end{array}$ & $\begin{array}{l}\text { Os dados gerados automaticamente } \\
\text { permitem análise e adequação da } \\
\text { estratégia utilizada - ação que não } \\
\text { seria realizada se os dados fossem } \\
\text { gerados manualmente. }\end{array}$ & $\begin{array}{l}\text { Se não houvesse essa facilidade } \\
\text { gratuita [dados gerados } \\
\text { automaticamente], talvez ficasse } \\
\text { em segundo plano. }\end{array}$ \\
\hline $\begin{array}{l}\text { Divulgação de } \\
\text { produtos e da } \\
\text { empresa }\end{array}$ & $\begin{array}{l}\text { Utilização das RSV na divulgação e } \\
\text { comercialização dos seus produtos e } \\
\text { serviços (Brandão, 2016). }\end{array}$ & $\begin{array}{l}\text { As RSV funcionam como a vitrine da } \\
\text { loja, onde podem divulgar/expor seus } \\
\text { produtos através das publicações. }\end{array}$ & $\begin{array}{l}\text { Possibilitam alcançar um bom } \\
\text { público e tornaram-se locais para } \\
\text { divulgar os produtos. }\end{array}$ \\
\hline Canal de vendas & $\begin{array}{l}\text { A rapidez, o número de visualização } \\
\text { de links de vendas e as facilidades } \\
\text { de acesso e divulgação tornaram-nas } \\
\text { ótimos canais de vendas (Gomes \& } \\
\text { Mondo, 2016). }\end{array}$ & $\begin{array}{l}\text { As RSV são o principal canal de } \\
\text { vendas das empreendedoras e as } \\
\text { negociações (consulta de preços } \\
\text { e fechamento da venda) são feitas } \\
\text { através delas. }\end{array}$ & $\begin{array}{l}\text { Possibilidade de fazer a venda } \\
100 \% \text { online, sem precisar de } \\
\text { uma loja física. }\end{array}$ \\
\hline $\begin{array}{l}\text { Emancipação } \\
\text { financeira }\end{array}$ & $\begin{array}{l}\text { Possibilita fortalecer a marca, } \\
\text { ampliar as receitas e se tornar } \\
\text { autossustentáveis financeiramente } \\
\text { (Brandão, 2016). }\end{array}$ & $\begin{array}{l}\text { Possibilitaram a manutenção } \\
\text { e expansão do negócio, e a } \\
\text { independência financeira de dois dos } \\
\text { três casos. }\end{array}$ & $\begin{array}{l}\text { Se ainda não alcançaram a } \\
\text { emancipação financeira, vão } \\
\text { alcançar. }\end{array}$ \\
\hline Captação de clientes & $\begin{array}{l}\text { As RSV são um instrumento poderoso } \\
\text { para a captação e manutenção de } \\
\text { clientes (Visentini et al., 2017). }\end{array}$ & $\begin{array}{l}\text { A captação dos clientes é feita } \\
\text { exclusivamente pelas RSV, através } \\
\text { das publicações. }\end{array}$ & $\begin{array}{l}\text { Ferramenta eficaz de captação } \\
\text { de clientes para fazer negócio. }\end{array}$ \\
\hline $\begin{array}{l}\text { Aumento da } \\
\text { visibilidade e alcance } \\
\text { da empresa }\end{array}$ & $\begin{array}{l}\text { O uso o torna mais visível aos demais, } \\
\text { ampliando seu alcance e popularidade } \\
\text { (Recuero, 2009). }\end{array}$ & $\begin{array}{l}\text { Permitem que pessoas de outras } \\
\text { cidades acompanhem e comprem da } \\
\text { sua empresa. }\end{array}$ & $\begin{array}{l}\text { Possibilitam alcançar um bom } \\
\text { público com baixo investimento e } \\
\text { sem limitação geográfica. }\end{array}$ \\
\hline
\end{tabular}

Fonte: Elaboração própria, adaptada da literatura.

Da Tabela 3, em que se comparam as contribuições encontradas na literatura e as percepções das empreendedoras e da especialista, destacam-se quatro contribuições que são citadas como as mais percebidas: divulgação de produtos (Brandão, 2016), canal de vendas (Gomes e Mondo, 2016), captação de clientes (Visentini et al., 2017) e aumento da visibilidade e alcance da empresa (Recuero, 2009).

A Tabela 4 apresenta contribuições percebidas pelas empreendedoras e não encontradas na revisão de literatura.

Tabela 4 - Contribuições das RSV na perspectiva das empreendedoras

\begin{tabular}{|l|l|}
\hline \multicolumn{1}{|c|}{ Contribuição } & \multicolumn{1}{c|}{ Percepção das empreendedoras } \\
\hline Demanda inicial de clientes. & $\begin{array}{l}\text { Duas empreendedoras começaram o negócio por uma demanda vinda exclusivamente das } \\
\text { RSV e todas utilizam as redes desde o início do negócio para conseguir clientes. }\end{array}$ \\
\hline $\begin{array}{l}\text { Importante para a manutenção do } \\
\text { empreendimento. }\end{array}$ & As empreendedoras não manteriam seus negócios atualmente sem o uso das redes sociais. \\
\hline
\end{tabular}

Fonte: Elaboração própria.

Constata-se que as redes sociais contribuíram para um empreendedorismo por oportunidade (Global Entrepreneurship Monitor, 2018), ou seja, elas também estimulam o empreendedorismo feminino, mesmo que de forma indireta, contribuindo para a independência dessas mulheres.

Portanto, os resultados sinalizam que as RSV se tornaram ferramentas para a criação e manutenção de empreendimentos femininos, além de apresentarem contribuições em diversas áreas da empresa. Elas evoluíram do papel de apoio ao negócio para se tornaram elemento essencial para as empreendedoras desde o início do empreendimento. Sua utilização pode ser cada vez mais otimizada para que os usuários possam chegar a resultados melhores e seu uso auxilie na identificação de novos empreendimentos.

\section{CONSIDERAÇÕES FINAIS}

Esta pesquisa teve o objetivo de identificar as contribuições do uso de redes sociais virtuais (RSV) para o empreendedorismo feminino. Com base no estudo de casos múltiplos, foi possível identificar nove contribuições corroboradas pela literatura, a saber: interação e relacionamento com os clientes; fortalecimento e influência da marca; 
custos menores; mensuração de resultados; divulgação de produtos; canal de vendas; emancipação financeira; captação de clientes e aumento da visibilidade e alcance da empresa.

Duas contribuições adicionais foram identificadas nos casos estudados, sinalizando que: i) as RSV apresentaram grande relevância antes do início do empreendimento, estando presentes na identificação da oportunidade de negócio e sendo responsáveis pela demanda inicial de clientes; ii) as RSV permanecem essenciais aos empreendimentos mesmo depois da sua consolidação, representando uma das bases do negócio, ao ponto de que, sem elas, o negócio deixaria de existir.

A contribuição da pesquisa para a academia se concentra na identificação de benefícios de tecnologia da informação e comunicação (TIC) em ambientes voláteis e contingenciais (redes sociais), o que ainda é um desafio para os estudos sobre valor de TI. Nesse sentido, a pesquisa apresenta algumas contribuições para compreensão do valor negócio da TI. Os resultados também contribuem com as empreendedoras, no sentido de conhecerem quais contribuições o uso das RSV podem trazer para o negócio, possibilitando que explorem com mais consciência os recursos, entendam como essas redes podem fortalecer e expandir o negócio, além da possibilidade do seu uso para a identificação de novas demandas de mercado.

Esta pesquisa apresenta limitações quanto ao número de casos estudados. Como alternativas de mitigação dessa limitação foram utilizadas outras fontes de evidências, como a entrevista com uma especialista em empreendedorismo feminino e a observação direta das redes sociais, com o objetivo de obter elementos para triangulação de dados. Outra limitação encontra-se na literatura, pois se trata de um tema com abordagem incipiente e com reduzido número de investigações específicas sobre o uso das RSV para o empreendedorismo feminino, sendo os estudos encontrados, em sua maioria, sobre o uso para empresas já estabelecidas ou consolidadas fisicamente.

Em pesquisas futuras sugere-se investigar a associação entre o uso de redes sociais e o desempenho dos empreendimentos com uso intensivo de tecnologia, bem como o tamanho dos impactos do uso de RSV sobre o empreendedorismo, adotando uma abordagem quantitativa. Adicionalmente, é relevante estudar o papel das redes sociais como motivadoras do início do empreendimento.

\section{REFERÊNCIAS}

ALPERSTEDT, G. D.; FERREIRA, J. B.; SERAFIM, M. C. Empreendedorismo feminino: dificuldades relatadas em histórias de vida. Revista de Ciências da Administração, [S. I.], v. 16, n. 40, p. 221-234, 2014.

BARDIN, L. Análise de conteúdo. 4. ed. Lisboa: Edições 70, 2011.

BATISTA, H. R.; GASPAR, M. A.; SASSI, R. J. Framework de mineração de opiniões aplicado a dados de redes sociais para pequenas e médias empresas. Revista Gestão \& Tecnologia, [S. I.], v. 20, p. 218-242, 2020.

BERTOLAMI, M.; ARTES, R.; GONÇALVES, P. J.; HASHIMOTO, M.; LAZZARINI, S. G. Sobrevivência de empresas nascentes: influência do capital humano, social, práticas gerenciais e gênero. Revista de Administração Contemporânea, [S. I.], v. 22, n. 3, p. 311-335, 2018.

BRAGA, G. C.; COELHO, M. D. F. Marketing digital: estratégias de blogueiras de moda. Marketing \& Tourism Review, [S. I.], v. 3, n. 2, p. 1-20, 2018.

BRANDÃO, M. Marketing digital e redes sociais: um estudo de caso na formação de mulheres empreendedoras da Economia Solidária no Estado Piauí. 2016. Dissertação (Mestrado em Tecnologia e Gestão em Educação a Distância) - Universidade Federal Rural de Pernambuco, Recife, 2016.

CETIC. TIC empresas. [S. I.]: Cetic, 2017.

CONCEIÇÃO, R. A. M. Imagem técnica e imagem turística: considerações sobre o Instagram como motivador para o turismo. Caderno Virtual de Turismo, [S. I.], v. 20, n. 1, p. 1-15, 2020.

CORREIO, W. DE S. C.; CORREIO, J. C. L. DOS S.; CORREIO, G. S. P.; CORREIO, N. R. de A. O poder das redes sociais online nas manifestações ocorridas no Brasil. Revista De Tecnologia Aplicada, [S. I.], v. 5, n. 1, p. 7-31, 2016.

DESIDÉRIO, P. H. M.; BITTENCOURT, I. M.; CARDOSO SOBRINHO, C. A..; NEDER, R. The social media in the projection of regional startups: observations of the profile of the companies in the social networks. International Journal of Innovation, [S. I.], v. 5, n. 3, p. 421-434, 2017.

FERNANDES, N. P.; D'AVILA, L. C.; CRUZ, A. P. C.; PEREIRA JUNIOR, E. F. Z. Quem é o empreendedor? a busca 
por uma definição do conceito através da produção científica brasileira. Revista Brasileira de Gestão e Inovação, [S. I.], v. 7, n. 3, p. 26-62, 2020.

FERREIRA, C.; CAMPOS, R. C.; NAVES, F. M.; DA SILVA, W. B.; FERNANDES, G. G. Marketing digital e redes sociais como oportunidade de inovação para micro e pequenas empresas: um estudo realizado com varejistas da cidade de Lavras MG. Revista Foco, [S. I.], v. 12, n. 2, p. 88-111, 2019.

FERREIRA, G. F.; BASTOS, S. A. P.; D'ANGELO, M. J. A look at women's transition from formal labor to self-employment based on endogenous stimuli. Revista de Administração Mackenzie, [S. I.], v. 19, n. 2, p. 1-26, 2018.

FERREIRA, N. S.; ARRUDA FILHO, E. J. M. Facebook e Whatsapp: uma análise das preferências de uso. Reuna, [S. I.], v. 20, n. 3, p. 47-64, 2015.

FORMANSKI, F. N.; GONÇALO, C. R.; ANGELONI, M. T.; FORMANSKI, J. G. Estratégia de relacionamento com o cliente por meio das redes sociais digitais: um estudo de caso no banco do Brasil S/A. Reuna, [S. I.], v. 18, n. 2, p. 83-98, 2013.

FREITAS, R. K. V. DE; TEIXEIRA, R. M. Identificação de oportunidades empreendedoras por mulheres. Revista Economia e Gestão, [S. I.], v. 16, n. 44, p. 81-108, 2016.

GIL, A. C. Métodos e técnicas da pesquisa social. 6 ed. São Paulo: Atlas, 2008.

GIMENEZ, F. A. P.; FERREIRA, J. M.; RAMOS, S. C. Empreendedorismo feminino no Brasil: gênese e formação de um campo de pesquisa. Revista de Empreendedorismo e Gestão de Pequenas Empresas, [S. I.], v. 6, n. 1, p. 40-74, 2017.

GLOBAL ENTREPRENEURSHIP MONITOR. Empreendedorismo no Brasil. Relatório executivo 2018. [S. I.]: GEM, 2018.

GOMES, A. F.; SANTANA, W. G. P.; ARAÚJO, U. P.; MARTINS, C. M. F. Empreendedorismo feminino como sujeito de pesquisa. Revista Brasileira de Gestão de Negócios, [S. I.], v. 16, n. 51, p. 319-342, 2014.

GOMES, B. L.; MONDO, T. S. A Contribuição das redes sociais na captação de clientes sob a percepção dos gestores hoteleiros. Revista Brasileira de Marketing, [S. I.], v. 15, n. 2, p. 177-194, 2016.

IBQP. Instituto Brasileiro de Qualidade e Produtividade. Análise dos resultados do GEM 2017 por faixa etária. [S. I.]: Sebrae, 2018.

JONATHAN, E. G. Mulheres empreendedoras: medos, conquistas e qualidade de vida. Psicologia em Estudo, [S. I.], v. 10, n. 3, p. 373-382, 2006.

MACLENNAN, M. L. F.; LUGOBONI, L. F.; ZITTEI, M. V. M.; TABATA, R. Y.; CORREA, H. L. Associação entre intensidade de uso de mídias sociais, credibilidade e decisão de compra. Revista de Gestão e Tecnologia, [S. I.], v. 4 , n. 2, p. $65-77,2014$.

NUNES, C. N. F.; CRUZ, L. A. M. Um estudo do comportamento de mulheres empreendedoras no Distrito Federal. [S. I.: s. n.], 2009.

PINOCHET, L. H. C.; PACHELLI, I. L.; DA ROCHA, F. M. M. Uso de métricas em mídias sociais e indicadores de desempenho do site e sua relação com o valor da marca em empresas de cosméticos no Brasil. Revista Brasileira de Marketing, [S. I.], v. 17, n. 1, p. 80-99, 2018.

RECUERO, R. Redes sociais na Internet. [S. I.]: Sulina, 2009.

ROCHA, T. V.; JANSEN, C. L. S.; LOFTI, E.; FRAGA, R. R. Estudo exploratório sobre o uso das redes sociais na construção do relacionamento com clientes. Revista Brasileira de Gestão de Negócios, [S. I.], v. 15, n. 47, p. 262-282, 2013.

SANTOS, J. M., SILVA, M. D. S., FRADE, C. M.; DE SOUSA, F. R. L. Mídias digitais como canal de comunicação 
em empresas do ramo de vestuário e moda da cidade de Santa Luzia/PB. Conhecimento Interativo, [S. I.], v. 13, n. 1, p. 330-345, 2019.

SEBRAE. Data Sebrae indicadores: total de empresas. [S. I.]: Sebrae, 2014.

SEBRAE. Data Sebrae indicadores: número de empreendedores. [S. I.]: Sebrae 2018a.

SEBRAE. Sexo dos empreendedores. [S. I.]: Sebrae 2018b.

SEBRAE. Tranformação digital das MPE 2018. [S. I.]: Sebrae 2018c.

SEBRAE. Relatório especial: empreendedorismo feminino no Brasil. [S. I.]: Sebrae 2019.

SILVA, A. S. DE B.; GUIMARÃES, J. DE C. Empreendedorismo feminino: perfil no segmento da beleza e da estética.

Revista da Micro e Pequena Empresa, [S. I.], v. 12, n. 2, p. 53-71, 2018.

SILVA, M. S. DA; MAINARDES, E. W.; LASSO, S. V. Características do empreendedorismo feminino no Brasil. Revista Gestão e Desenvolvimento, [S. I.], v. 13, n. 2, p. 150-167, 2016.

SOUZA, M. J. B. DE; TRINDADE, F. D. M.; FREIRE, R.; LYRA, F. R. Potencial empreendedor de empresárias do setor turístico de Florianópolis (SC). Revista Alcance, [S. I.], v. 23, n. 4, p. 455-474, 2016.

TERRA, C. F. A comunicação organizacional em tempos de redes sociais online e de usuários- mídia. In: CONGRESSO BRASILEIRO DE CIÊNCIAS DA COMUNICAÇÃO, 32., 2009, Curitiba. Anais [...]. Curitiba: Intercom, 2009. p. 1-15.

VERGA, E.; SOARES DA SILVA, L. F. Empreendedorismo: evolução histórica, definições e abordagens. Revista de Empreendedorismo e Gestão de Pequenas Empresas, [S. I.], v. 3, n. 3, p. 3-30, 2014.

VERGARA, S. C. Métodos de pesquisa em administração. 5.ed. Rio de Janeiro: Atlas, 2012.

VISENTINI, M. S.; RADONS, D. L.; CHAGAS, F. B. Somos todos iguais virtualmente? analisando os moderadores idade, gênero e experiência no uso do facebook. Revista Ciências Administrativas, [S. I.], v. 23, n. 3, p. 459-475, 2017.

YIN, R. K. Estudo de caso: planejamento e métodos. Porto Alegre: Bookman, 2005.

\section{Contato:}

Darah de Mathias Fontana

E-mail: darah_fontana@hotmail.com

Deyvison de Lima Oliveira

E-mail: deyvilima@gmail.com

Elder Gomes Ramos

E-mail: elder.gomes@unir.br

Ariadne dos Santos Massaro

E-mail: ariadnemassaro@gmail.com

Submetido em: 24/01/2020

Revisado em: $23 / 09 / 2020$

Aprovado em: 07/12/2020 